\title{
Detection of oestrous-related odour in ewe urine by rams
}

\author{
M. J. Blissitt*, K. P. Bland and D. F. Cottrell \\ Department of Preclinical Veterinary Sciences, University of Edinburgh, EH19 1QH, UK
}

\begin{abstract}
The ability of rams to discriminate between urine odour of oestrous ewes and urine odours from ewes at other days of the oestrous cycle was determined using operant conditioning techniques. Rams could discriminate between the odour of urine of oestrous ewes and the odours of urine from ewes at day 6 to day 1 before oestrus and from ewes at day 4 to day 10 after oestrus. Rams did not discriminate between odours of urine samples from different ewes in oestrus, or between urine odour of oestrous ewes (day 0 ) and urine odours from ewes at day 1 to day 3 after oestrus. These results support the hypothesis that ewes in oestrus produce an odour in urine that is detectable by rams.
\end{abstract}

\section{Introduction}

Rams use olfaction to detect ewes in oestrus in a flock (Lindsay, 1965; Fletcher and Lindsay, 1968; Rouger, 1973; Smith, 1975). Anosmic rams approach oestrous and nonoestrous ewes randomly, whereas intact rams preferentially approach ewes in oestrus (Lindsay, 1965; Fletcher and Lindsay, 1968) and can discriminate between the odours of urine of oestrous and non-oestrous (mid-cycle) ewes (Blissitt, 1989; Blissitt et al., 1990a, b). We show here that rams can discriminate between odour of urine of ewes in oestrus and the odour of urine from all other days of the cycle except the 3 days following oestrus.

\section{Materials and Methods}

Six rams, of various domestic breeds, were trained to discriminate between the odours of urine of ewes in oestrus (day 0 ) and those not in oestrus (day 9) using simultaneous two-choice olfactory discriminations in a purpose-built, automated, experimental crate (Fig. 1) (Baldwin and Meese, 1977; Blissitt, 1989; Blissitt $e t$ al., 1990a). Four rams were elderly retired stud rams and two were mature but sexually inexperienced. In each experiment of 50 consecutive choices, two odours were offered simultaneously from separate odour nozzles above two switches. All urine odours were produced by passing air over $10 \mathrm{ml}$ of urine warmed to $39^{\circ} \mathrm{C}$ in a temperature-controlled waterbath. Odours were delivered at the nozzles at a flow rate of $11 \mathrm{~min}^{-1}$ and a velocity of $0.59 \mathrm{~m} \mathrm{~s}^{-1}$. Rams were trained to use their noses to press the switch under the nozzle producing urine odour from ewes in oestrus and obtain a food reward of $10 \mathrm{~g}$ of whole oats. Presses on the switch beneath the nozzle with odour from ewes not in oestrus were unrewarded and counted as errors. The odour positions were varied between nozzles by slide valves according to the series of Fellows (1967). These series describe orders of alternating

\footnotetext{
*Correspondence and present address: Animal Health Office, Russell House, King Street, Ayr, KA8 0BE, UK.

Received 15 September 1993.
}

stimuli that should be used in two-choice discrimination experiments to minimize position preference. After 25 rewards, determined by a selected series, odour positions were changed by solenoid valves at the nozzles. After the other 25 rewards, dummy solenoid valves imitated the sound of the nozzle solenoids, but the odour positions were unchanged. No confounding aural stimuli were available to influence choices made by the rams. Rams were trained to a fixed schedule ratio of four. Thus, four presses on the correct switch were needed to obtain a reward. The error score system supposed that rams would press either four or eight times depending on whether their first choice was correct and that they had changed to the opposite panel when they received no reward after four presses. They would therefore, press on average six times per reward and with 50 choices would press 300 times, 100 of which would be incorrect. The number of errors expected by chance, if the rams were not discriminating between odours, would therefore be 100 . Below this number the rams could be said to be discriminating between odours and the number of errors could be used to grade the ability to discriminate. The positive discriminative stimulus was always odour of urine from ewes in oestrus. The negative discriminative stimulus, odour of urine from ewes not in oestrus, was then varied to cover every other day of the cycle (from 6 days before oestrus to 10 days after oestrus). Days before oestrus were established retrospectively using a teaser ram to determine standing oestrus.

Twelve ewes used as urine donors were housed at a separate site, and were checked daily for oestrous behaviour using a vasectomized ram. Ewes in oestrus were not allowed to mate with the vasectomized ram until urine had been collected. Urine from oestrous ewes was collected on days of 'standing oestrus' (day 0) using a plastic pot attached to the peri-vulval wool. Urine from ewes not in oestrus was collected into a hand-held plastic beaker during micturition elicited by approaching the ewe. Immediately after urination the urine was transferred to $5 \mathrm{ml}$ glass containers filled to exclude air and stored at $39^{\circ} \mathrm{C}$. Urine collections were made between $08: 00$ and $10: 30 \mathrm{~h}$ and all samples were used within $\mathrm{I} \mathrm{h}$ of collection. Different ewes donated urine for consecutive experiments.

Downloaded from Bioscientifica.com at 04/26/2023 12:34:53PM 

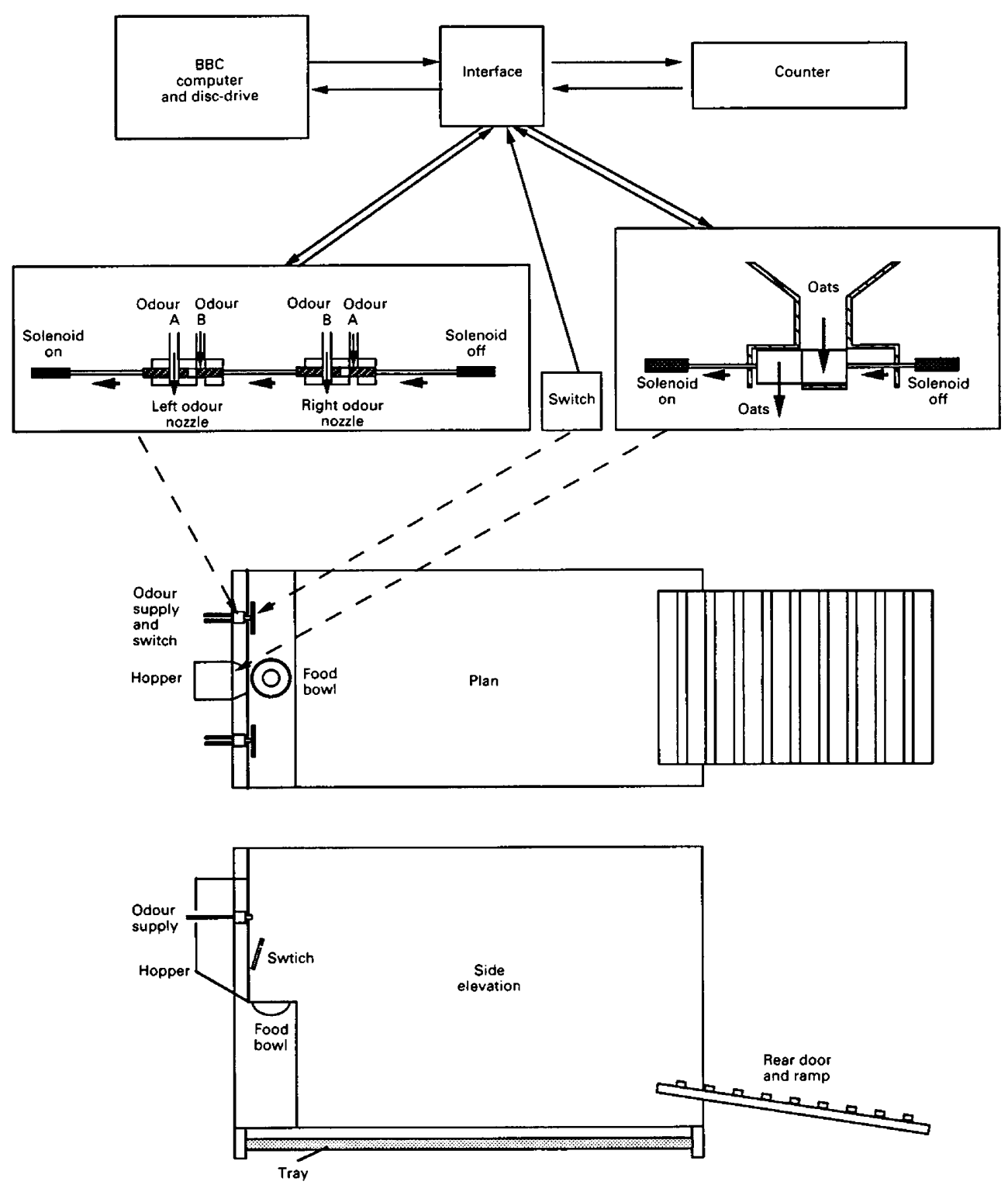

Fig. 1. The plan and side elevation of the experimental crate are shown at the bottom of the figure. The crate was $2 \mathrm{~m}$ long, $90 \mathrm{~cm}$ wide and had solid sides $1.2 \mathrm{~m}$ high. The ram entered the crate by a ramp that lifted up to form the rear door. The front panel of the crate offered the ram a choice of two $10 \mathrm{~cm}$ square spring switches, each beneath an odour nozzle. Below the two switches was a centrally positioned food bowl. The upper part of the figure gives an overview of how the solenoid-operated slide valves controlling the odour nozzles and the food-reward dispenser were controlled, via an interface, by a BBC microcomputer according to the nature of the input signals from the spring switches. A counter recorded the scores.

Two elderly rams were tested with urine from ewes at all days of the cycle. Data were obtained for a further two elderly rams on all but 2 days, but the data for the other two rams were much less complete.

Experiments were conducted between October and March, the natural breeding season of sheep in the Northern hemisphere.

\section{Results}

Rams could discriminate between the odour of urine from ewes in oestrus and the odour of urine from day 6 to day 1 before oestrus and from day 4 to day 10 after oestrus. Error scores were $50 \%$ or less below those expected by chance. Rams did not discriminate between the odours of urine samples from different ewes at oestrus, or between the odour of urine at oestrus (day 0 ) and urine odours from day 1 to day 3 after oestrus (Fig. 2). Error scores were markedly above the level of chance in the absence of discrimination. This is due to rams pressing the incorrect switch more than four times before changing to the correct one when unable to discriminate. This behaviour is a feature of rams (Blissitt, 1989) and other mammals (Mackintosh, 1974). 


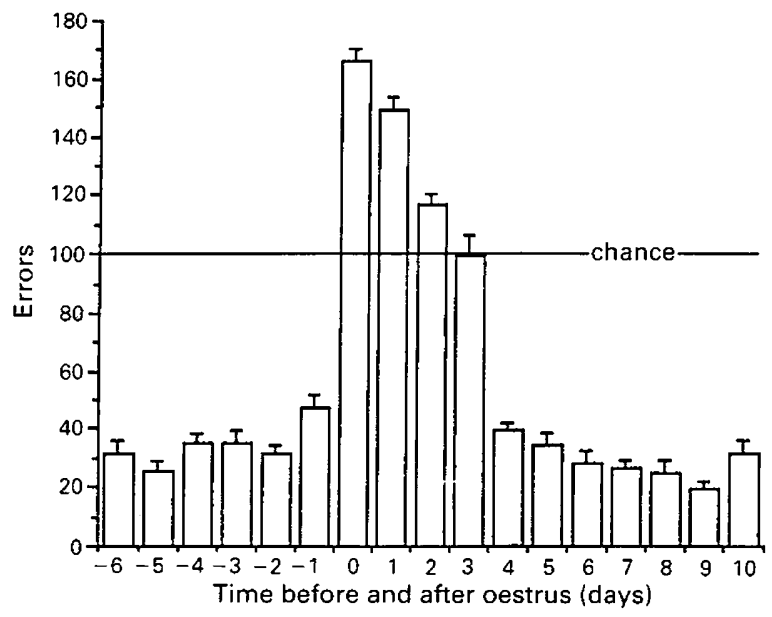

Fig. 2. Mean error scores $(+S E)$ achieved by rams discriminating between oestrous urine odour and urine odours from before (day -6 to day -1 ) during (day 0 ) and after (days $1-10$ ) oestrus. Each mean value was calculated from the results of 16 olfactory discrimination trials (four trials by four rams on different days using different combinations of donor ewes).

\section{Discussion}

These results support the hypothesis that female sheep in oestrus produce an odour in urine that is detectable by rams. The odour subsequently wanes to become undetectable 4 days after oestrus. The consistency of discriminating ability between rams, as indicated by the small SES of the pooled data, is very marked. Observations of videotaped trials demonstrated that the rams both positively discriminated for the odour of urine from ewes in oestrus and negatively discriminated against the odour from urine of ewes that were not in oestrus.

In the trials using odour of urine from different ewes at oestrus and trials using odour of urine from ewes at oestrous versus odour of urine from ewes 1 day after oestrus, the rams became very confused and made many errors. This behaviour has previously been observed when identical odours have been presented to each nozzle in control experiments. Such experiments should be kept to an absolute minimum.

A stimulus such as odour from ewe urine has different properties. The discriminating properties used by rams in these experiments were related to different stages of the oestrous cycle and not to the identity of donor ewes. However, rams can discriminate between urine from individuals if trained to do so (Baldwin and Meese, 1977; M. J. Blissitt, unpublished).

Ewes that are not in oestrus usually urinate in response to the approach of a ram, whereas ewes in oestrus do not (Banks, 1964; Geist, 1971; Bland and Jubilan, 1987). Urination by ewes may be a non-contact communication that allows rams to determine efficiently the oestrous status of the ewe under free-range conditions in an energy-efficient manner. Ewes can avoid disturbance by signalling the non-oestrous state. The ram focuses his attentions on the voided urine and exhibits the 'flehmen response' (Banks, 1964), which is thought to facilitate the entry of urine into the vomeronasal organ for chemosensory analysis (Fraser, 1968; Estes, 1972; Ladewig and Hart, 1980). However, the chemoreceptors discriminating between the odours of ewes in oestrus and not in oestrus are located in the main olfactory epithelium (Blissitt et al., 1990b), and rams were never seen to exhibit the flehmen response during operant discrimination experiments. It is not clear why ewes that are not in oestrus continue to produce oestrous-related odour for 3 days after oestrus. Lower concentrations of odour during this time may reflect the normal decay time of the odour concerned. It is possible that although rams continue to detect this odour in the period after oestrus, it is below the threshold for the stimulation of courtship and mating.

These results provide evidence for an oestrous-related odour in the urine of ewes and the methods used provide a bioassay for further elucidation of the source and nature of this odour.

The authors gratefully acknowledge the technical assistance of J. W. Brown, R. Lawson, T. Dyer and G. McConnell. M. J. Blissitt was supported by a Veterinary Schools Research Fellowship from the Agriculture and Food Research Council.

\section{References}

Baldwin B and Meese GB (1977) The ability of sheep to distinguish between conspecifics by means of olfaction Physiology and Behaviour 18 803-808

Banks EM (1964) Some aspects of sexual behaviour in domestic sheep (Ovis aries) Behaviour $23249-279$

Bland KP and Jubilan BM (1987) Correlation of flehmen by male sheep with female behaviour and oestrus Animal Behaviour 35 735-738

Blissitt MJ (1989) Olfactory Discrimination of Ewe Urine Odours by Rams. PhD Thesis, University of Edinburgh

Blissitt MJ, Bland KP and Cottrell DF (1990a) Discrimination between the odours of fresh oestrous and non-oestrous ewe urine by rams Applied Animal Behaviour Science 25 51-59

Blissitt MJ, Bland KP and Cottrell DF (1990b) Olfactory and vomeronasal chemoreception and the discrimination of oestrous and non-oestrous ewe urine odours by the ram Applied Animal Behavioural Science 27 325-355

Estes $\mathbf{R}$ (1972) The role of the vomeronasal organ in mammalian reproduction Mammalia 36 315-341

Fellows BF (1967) Chance stimulus sequences for discrimination tasks $P_{s y c h o-}$ logical Bulletin 67 87-92

Fletcher JC and Lindsay DR (1968) Sensory involvement in the mating behaviour of domestic sheep Animal Behaviour 16 410-414

Fraser AF (1968) Reproductive Behaviour in Ungulates. Academic Press, London, New York

Geist V (1971) Mountain Sheep. A Study in Behaviour and Evolution. University of Chicago Press, Chicago

Ladewig J and Hart BL (1980) Flehmen and vomeronasal organ function in male goats Physiology and Behaviour 24 1067-1071

Lindsay DR (1965) The importance of olfactory stimuli in the mating behaviour of the ram Animal Behaviour 13 75-78

Mackintosh NJ (1974) The Psychology of Animal Learning. Academic Press, London

Rouger Y (1973) Capacite sensorielle et niveau d'activité sexuelle chez le belier Préalpes et le belier lle de France. Comptes Rendus Hebdomadaires des Séances de l'Academie des Sciences (Paris) 276 3203-3206

Smith JF (1975) The influence of the senses of smell, sight and hearing on the sexual behaviour of rams Proceedings of the New Zealand Society for Animal Production 35212 